\title{
Cervicobraquialgia: síntoma inicial del síndrome de Pancoast
}

\author{
Meritxell Regí Bosque ${ }^{a}$, Iván Villar Balboab
}

\begin{abstract}
a EAP Can Serra.
${ }^{b}$ EAP Florida Sud. Instituto Catalán de la Salud. Unidad Docente Costa de Poniente. Hospitalet de Llobregat. Barcelona. España.
\end{abstract}

Correspondencia: Iván Villar Balboa. Correo electrónico: ivillar@ambitcp.catsalut.net

Recibido el 2 de febrero de 2013.

Aceptado para su publicación el 13 de marzo de 2013.

\section{RESUMEN}

El síndrome de Pancoast está producido por un tumor en el ápex pulmonar, con extensión local al plexo braquial inferior, cadena simpática paravertebral, cuerpos vertebrales y primera, segunda y tercera costillas. La mayoría de los casos de síndrome de Pancoast son causados por el carcinoma broncogénico de células no-pequeñas, principalmente por el carcinoma escamoso, seguido del adenocarcinoma y del carcinoma de células grandes. Las lesiones en el surco superior pueden dar lugar a dolor en el hombro y el brazo, síndrome de Horner y atrofia de los músculos de la mano. Debido a la ubicación periférica del tumor, síntomas tales como la tos, hemoptisis y disnea, son poco frecuentes hasta fases más avanzadas de la enfermedad.

PALABRAS CLAVE: Síndrome de Pancoast. Carcinoma pulmonar no microcítico. Dolor de hombro.

\section{ABSTRACT}

Cervicobrachialgia: initial symptom of Pancoast's syndrome

Pancoast syndrome is caused by a tumour in the pulmonary apex, with local spreading to the lower brachial plexus, paravertebral sympathetic chain, vertebral bodies, and first, second and third ribs. Most Pancoast syndrome cases are caused by non-small cell bronchogenic carcinoma, mainly by squamous cell carcinoma, followed by adenocarcinoma and large cell carcinoma. Lesions in the superior pulmonary sulcus can give rise to shoulder and arm pain, Horner syndrome and muscle atrophy of the hand. Owing to the peripheral location of the tumour, symptoms such as coughing, hemoptysis and dyspnoea are uncommon until more advanced stages of the illness.

KEYWORDS: Pancoast syndrome. Non-small-cell lung carcinoma. Shoulder pain.

\section{INTRODUCCIÓN}

El síndrome de Pancoast (SP) está producido por un tumor en el ápex pulmonar, con extensión local al plexo braquial inferior, cadena simpática paravertebral, cuerpos vertebrales y primera, segunda y tercera costillas. La causa más frecuente es el carcinoma broncogénico de células no-pequeñas, principalmente por el carcinoma escamoso ${ }^{1,2,3}$, seguido del adenocarcinoma y del carcinoma de células grandes. En algunas series predomina el adenocarcinoma ${ }^{4}$.

\section{OBSERVACIONES CLÍNICAS}

Paciente varón de 75 años, exfumador de 45 paquetes-año y con antecedentes patológicos de hipertensión arterial y dislipemia en tratamiento farmacológico. Acudió a consulta por cervicobraquialgia y dolor en región escapular derecha de 4 meses de evolución. No refería tos, fiebre, disnea ni dolor torácico. Tampoco presentaba síndrome tóxico.

En la exploración física no presentaba lesiones cutáneas en la zona anterior de hemitórax derecho ni en la extremidad superior derecha. No se objetivaron adenopatías. La movilidad y fuerza de ambas extremidades superiores (EESS) y balance articular estaban conservados. Los reflejos musculotendinosos de EESS fueron presentes y simétricos. A nivel de la columna cervical no presentaba dolor a la palpación de apófisis espinosas cervicales ni contractura de la musculatura paravertebral cervical. La auscultación cardiorrespiratoria 
fue normal.

Se solicitó radiografía $(\mathrm{Rx})$ de hombro derecho que no mostró alteraciones. La Rx cervical mostró osteofitosis, uncartrosis, disminución de discos intervertebrales C4-C5, C5-C6, C6-C7 y megatransversa en $\mathrm{C} 7$. Se inició tratamiento antiinflamatorio con diclofenaco $50 \mathrm{mg} / 8 \mathrm{~h}$.

El paciente reconsultó a la semana por persistencia de la clínica. Se solicitó Rx de tórax, electromiograma (EMG) de EESS y analítica. Se añadió al tratamiento analgésico gabapentina $300 \mathrm{mg} / 8 \mathrm{~h}$. El resultado del EMG fue normal. En la analítica presentó un hemograma y bioquímica normal, TSH normal y sólo destacaba un colesterol total de $207 \mathrm{mg} / \mathrm{dl}$ y un colesterol LDL de $137 \mathrm{mg} / \mathrm{dl}$. La Rx de tórax mostró una ocupación en ápex pulmonar derecho, no presente en radiografías previas (Figura 1).

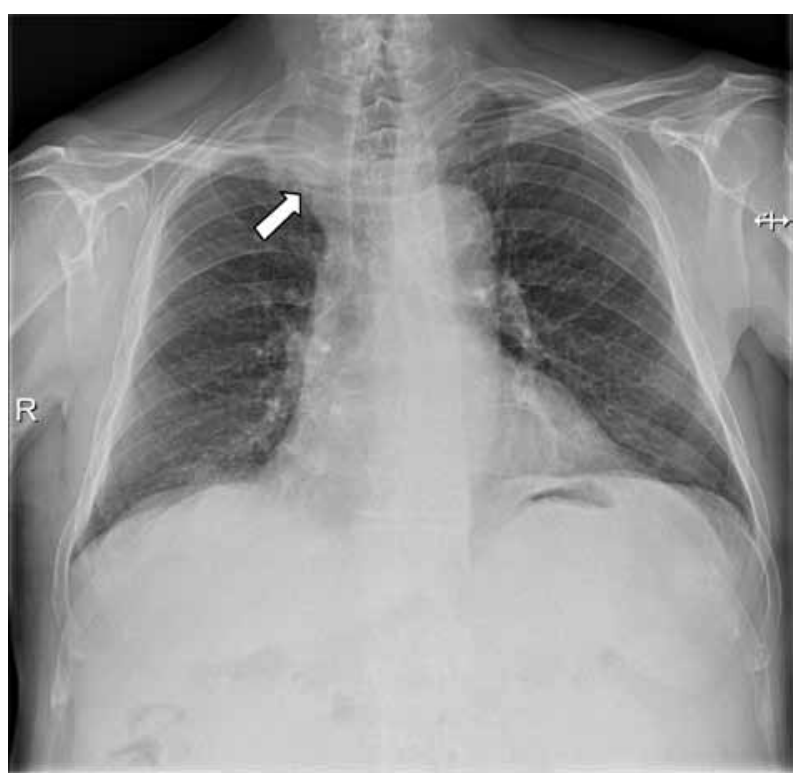

Figura 1. Radiografía de tórax postero-anterior: ocupación en ápex pulmonar derecho.

El paciente fue derivado a la Unidad de Diagnóstico Rápido de neoplasias pulmonares, donde se solicitó una Tomografía Computerizada torácica que mostró un proceso neoformativo apical derecho (Tumor de Pancoast) que infiltraba la pared torácica (arco costal, apófisis transversa y pedículo derecho D2) y probablemente grasa mediastínica, nódulo en lóbulo inferior derecho de $20 \mathrm{~mm}$, probablemente metastásico y adenopatías supraclaviculares derechas, en territorio paratraqueal bilateral, prevascular y perihiliar derecho. Posteriormente, se realizó punción transtorácica que confirmó el diagnóstico de carcinoma escamoso de pulmón.

\section{COMENTARIOS}

Los síntomas que definen el SP son: dolor en el hombro, debilidad y atrofia de los músculos de la mano y síndrome de Claude-Bernad-Horner ${ }^{1}$. Aunque estos síntomas son los que originalmente describió Pancoast, actualmente se acepta como síndrome de Pancoast toda aquella patología localizada en el ápex pulmonar que causa alguno de los síntomas, generalmente dolor en el trayecto del plexo braquial.

La clínica principal del SP se se describe a continuación ${ }^{3}$ :

- Dolor en el hombro: Es el síntoma inicial más frecuente. Suele irradiarse al territorio cubital del brazo y antebrazo; también al cuello, escápula, axila y a la región torácica. Se produce por afectación del octavo nervio cervical y del primer y segundo torácico, erosión de la primera, segunda y tercera costilla y afectación de cuerpos vertebrales o pleura parietal. A medida que avanza el cuadro, puede producirse debilidad y atrofia de los músculos intrínsecos de la mano y parestesias en el cuarto y quinto dedo siguiendo la distribución del nervio cubital. Los pacientes frecuentemente reciben tratamiento para la artrosis cervical o bursitis del hombro durante varios meses, con lo cual se produce un retraso en el diagnóstico.

- Síndrome de Claude-Bernad-Horner: Debido a la afectación del ganglio simpático estrellado y caracterizado por ptosis palpebral ipsilateral, miosis, enoftalmos y anhidrosis facial.

- Debido a la localización periférica de los tumores de Pancoast, síntomas como la tos, hemoptisis y disnea son poco frecuentes inicialmente, pero pueden aparecer en etapas más avanzadas.

- La afectación del nervio frénico o del recurrente, así como el síndrome de vena cava superior, son manifestaciones menos habituales.

El diagnóstico diferencial debe realizarse con otras entidades que pueden localizarse en el ápex pulmonar y por lo tanto pueden producir el SP (tabla 1)1.

Radiológicamente, el tumor a menudo es difícil de observar. Los hallazgos en la radiografía de tórax incluyen una radiopacidad de más de $5 \mathrm{~mm}$ en el ápex pulmonar, asimetría con respecto al ápex contralateral, masa apical o destrucción ósea ${ }^{1}$. La Tomografía Computerizada aporta información 


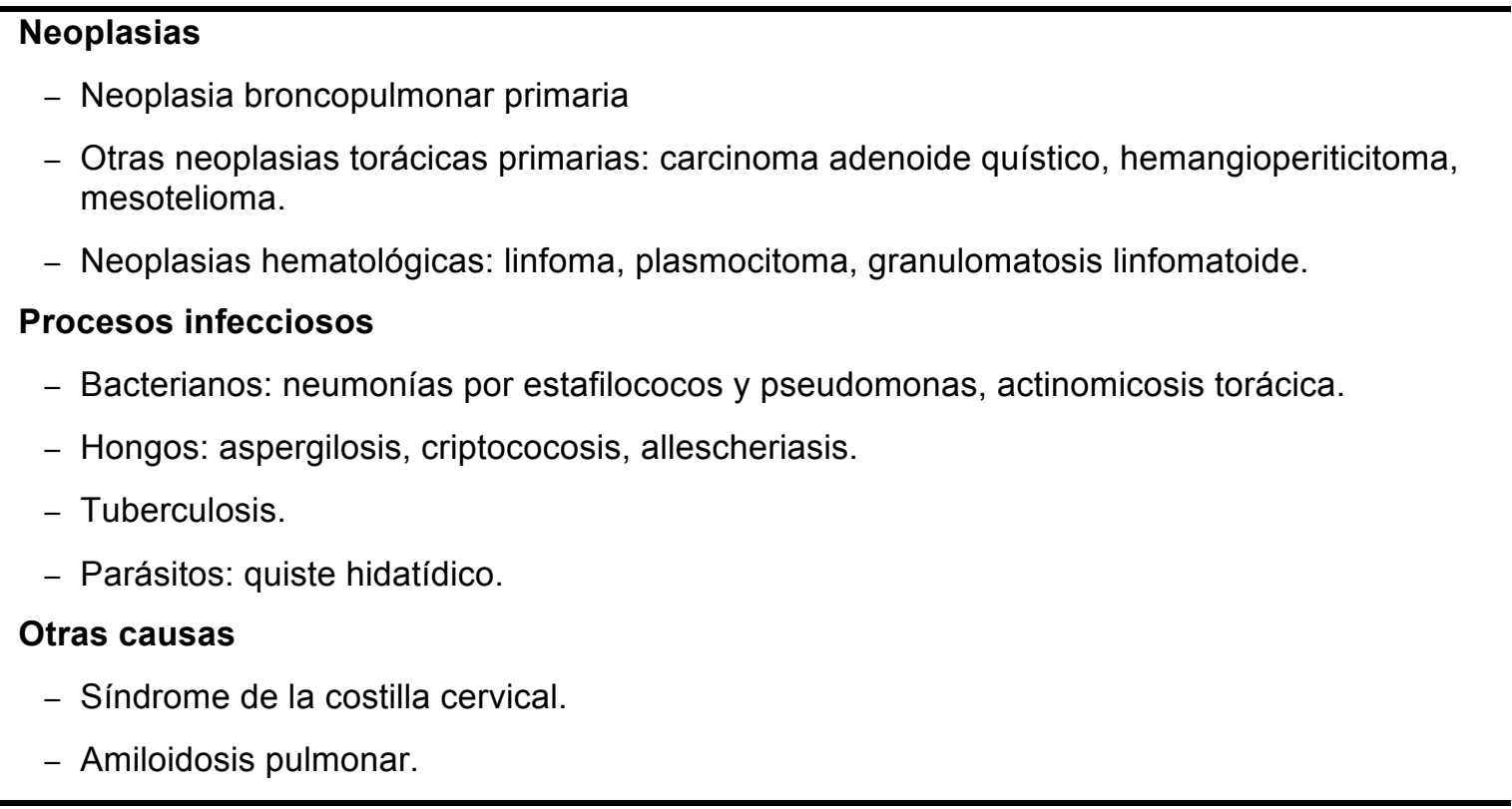

Tabla 1. Causas del síndrome de Pancoast. Modificado de: Arcasoy SM, Jett JR. N Engl J Med. 1997; 337: $1370-6^{1}$.

adicional en relación a la extensión local del tumor, la posible presencia de adenopatías mediastínicas, otros nódulos pulmonares, afectación vascular, y presencia de metástasis a distancia. En cuanto a la resonancia magnética, es especialmente útil para determinar la afectación de vasos subclavios, del plexo braquial y en la evaluación de los cuerpos vertebrales y del canal espinal. La tomografía por emisión de positrones(PET) permite la estadificación de las neoplasias de pulmón, ya que realiza una mejor valoración de la afectación ganglionar mediastínica y de las metástasis a distancia ${ }^{3}$. La angiorresonancia magnética permite evaluar con gran exactitud la posible afectación vascular de los vasos subclavios o braquiocefálicos ${ }^{5}$.

El diagnóstico definitivo requiere la demostración anatomopatológica del tumor. La ubicación marginal de los tumores del sulcus superior determina que la mejor técnica para el diagnóstico sea la punción transtorácica ${ }^{1,6}$. Por el contrario, la broncoscopia y la citología de esputo presentan una baja rentabilidad diagnóstica. La videotoracoscopia o la toracotomía se puede realizar si las técnicas menos invasivas no son diagnósticas ${ }^{1}$.

Con relación al tratamiento, la quimiorradioterapia combinada neoadyuvante seguido de la resección del tumor parece ser la mejor opción terapéutica en los casos resecables, con una menor tasa de recurrencia local y una mejor supervivencia. En los pacientes con enfermedad localmente avanzada no resecable se recomienda quimiorradioterapia ${ }^{3}$.

Los índices de supervivencia a los 5 años son del $30-40 \%$ en pacientes sin afectación de gánglios linfáticos y menores del $10 \%$ en aquellos con resección incompleta, afectación de gánglios mediastínicos o invasión de cuerpo vertebral ${ }^{3}$.

\section{BIBLIOGRAFÍA}

1. Arcasoy SM, Jett JR. Superior pulmonary sulcus tumors and Pancoast's syndrome. N Engl J Med. 1997; 337 (19): 1370-6.

2. Archie VC, Thomas CR Jr. Superior sulcus tumors: a minireview. Oncologist. 2004; 9 (5): 550-5.

3. Arcasoy SM, Jett JR, Schild SE. Pancoast's syndrome and superior (pulmonary) sulcus tumors. UptoDate (internet), (actualizada 28 de marzo de 2012; fecha de acceso: 8 de marzo de 2013). Disponible en: http://www.uptodate.com

4. Jones DR, Detterbeck FC. Pancoast tumors of the lung. Curr Opin Pulm Med. 1998; 4 (4): 191-7.

5. Laissy JP, Soyer P, Sekkal SR, Tebboune D, Servois V, Sibert $A$ et al. Assesment of vascular involvement with magnetic resonance angiography (MRA) in Pancoast syndrome. Magn Reson Imaging. 1995; 13 (4): 523-30.

6. Khosravi Shahi P. Síndrome de Pancoast (tumor de sulcus pulmonary superior): revision de la literatura. An Med Int 2005; 22(4):194-6. 